\title{
Effects of Lifestyle and Stress on the State of Defecation
}

\author{
Fumihiro Omasu ${ }^{1, *}$, Yuuka Yanai $^{2}$, Ayame Yamaguchi ${ }^{2}$, Miyu Yoshino ${ }^{2}$ \\ ${ }^{1}$ Department of Health and Nutrition, Faculty of Health and Nutrition, Yamagata Prefectural Yonezawa University of Nutrition Sciences, \\ Yamagata, Japan \\ ${ }^{2}$ Department of School Health, Faculty of Education, Kumamoto University, Kumamoto, Japan
}

\author{
Email address: \\ omasu@yone.ac.jp (F. Omasu) \\ *Corresponding author
}

\section{To cite this article:}

Fumihiro Omasu, Yuuka Yanai, Ayame Yamaguchi, Miyu Yoshino. Effects of Lifestyle and Stress on the State of Defecation. European Journal of Preventive Medicine. Vol. 9, No. 2, 2021, pp. 51-57. doi: 10.11648/j.ejpm.20210902.14

Received: March 15, 2021; Accepted: March 30, 2021; Published: April 13, 2021

\begin{abstract}
This study looks at constipation, which tends to appear as a physical symptom in daily life, among various health problems caused by turbulent eating habits and changes in social environment. In addition to these relationships between constipation and lifestyle, this study focused on the relationship between constipation and mental stress. Although there are few studies on how mental stress can cause constipation, it can be said that stress has some effect on the state of defecation. The purpose of this study was to clarify the relationship between the state of defecation, lifestyle, and stress among female college students. A questionnaire survey was conducted among 294 female college students used as subjects. Regarding lifestyle, it was revealed that the constipation group tended to lack sleep in comparison to the good condition group, and many in the constipation group tended to skip breakfast in comparison to the good condition group. It was also found that the constipation group tended to drink alcohol more frequently than the good condition group. There was no difference in the exercise category between the two groups. Regarding the relationship between the state of defecation and stress, it was found that the constipation group had a higher relationship than the good condition group in terms of both interpersonal relationships and achievement items when it came to negative life events. Furthermore, regarding positive life events, both interpersonal and achievement items were higher in the good condition group. It is considered that interpersonal relationships likely affect the state of defecation among female college students.
\end{abstract}

Keywords: Defecation, Lifestyle, Interpersonal and Achievement Stress

\section{Introduction}

According to a survey on defecation habits and constipation, constipation is more common among women, especially young women [1]. The effects of female hormones are cited as one of the reasons why constipation is more common in women than in men [2]. The peristaltic movement of the intestine is suppressed due to the influence of one female hormone, "progesterone," which easily causes constipation [2]. Although this effect occurs even during normal times, the effect is also said to become enhanced from after ovulation to before menstruation, with constipation likely to occur due to the loss of water in the large intestine caused by the action of progesterone that stores water and salt, resulting in hardening of the stool [2].

Although eating habits, lack of exercise, water deficiency, etc. are mainly cited as lifestyle habits that are considered to be the cause of constipation [3-7], it is also known that the physical constitution of a person and the influence of mental stress are also related [8]. In addition to these relationships between constipation and lifestyle, this study focused on the relationship with mental stress. Although there are few studies on how mental stress can cause constipation, it can be said that stress has some effect on the state of defecation [9]. Spastic constipation is one cause of constipation due to mental stress [10]. While the balance between sympathetic nerves and parasympathetic nerves is important for normal bowel movements, long-term exposure to mental stress causes the parasympathetic nerves to become hypertonic, promoting intestinal peristalsis and making defecation difficult, a state known as spastic constipation, which is a type of constipation with irritable bowel syndrome. It is 
believed that spastic constipation indicates a strong desire for defecation despite it being difficult to defecate, with intermittent abdominal pain and abdominal bloating, making the stool thin like rabbit feces and leaving a strong feeling of residual stool [11]. In addition, it is easily affected by psychological factors and is said to sometimes be alternatively exhibited in shifts with diarrhea [12]. Therefore, this study uses two stress scale items, "interpersonal relationships" and "achievement," as psychological factors.

This study focused on constipation, which tends to appear as a physical symptom on a daily basis, and examined the relationship between the state of defecation and the lifestyle of college students, which are thought to easily cause defecation abnormalities due to changes in living environment.

\section{Methods}

The subjects were 294 female college students. We distributed questionnaires and received answers using an anonymous self-administered method.

\subsection{Lifestyle}

The items of sleep, breakfast, alcohol drinking, smoking, and exercise, which are considered related to the state of defecation, were asked as questions, with regard to the lifestyle of the previous month. The question items regarding sleep included bedtime, wake-up time, and hours of sleep. The questions on how often they eat breakfast included four possible answers from which to choose: "Eat daily"; "Eat 2-3 times a week"; "Eat 4-5 times a week"; and "Never eat." The questions on how often they would drink included four possible answers from which to choose: "Drink daily"; "Drink 2-3 times a week"; "Drink 2-3 times a month"; and "Almost never." Regarding smoking, there were two possible answers from which to choose: "Smoke"; and "Do not smoke," with the respondents specifically answering how many cigarettes they smoke a day. The questions on exercise included four possible answers from which to choose: "Almost every day"; "2-4 times a week"; "About once a week"; and "Almost never."

\subsection{State of Defecation}

With regard to the state of defecation in the previous month, we asked them to answer in regard to bowel movements, number of bowel movements, regularity, and bowel movement time.

The answer regarding bowel movements included three options from which to choose: "Constipation"; "Normal"; and "Diarrhea." Regarding the number of defecations, the answers included five options from which to choose: "Once a day"; "Twice a day"; "More than three times a day"; "Once every two days"; "Once every three to four days"; and "Other." Regarding the regularity of defecation, the answers included five options from which to choose: "After waking up"; "After breakfast"; "After lunch to evening"; "Irregular"; and "Other." The answers regarding the time required to defecate, included three options from which to choose: "Within 5 minutes"; "Within 5 to 10 minutes"; and "More than 10 minutes." Those who met the definition of constipation in Rome III [13-15] were classified as being in the constipation group, while those who did not meet the definition of constipation were classified as being in the good condition group.

\subsection{Interpersonal Stress/Achievement}

The stress survey collected negative life event items, referencing the general life event scale of Japanese college students $[16,17]$ and with positive life events also adopted, from topics in the same area as negative life events, with reference to Needles and Abramson [18]. Negative and positive life events consist of 30 items each, while each life event consists of 15 items in the interpersonal and achievement category.

\subsection{Statistical Analysis}

The difference in frequency between the good condition group and the constipation group, in terms of lifestyle and state of defecation, was analyzed using the chi-square test. The comparison of scores was analyzed by the Welch's test for the category of stress.

\section{Results}

The results were tabulated by focusing on the state of defecation of female college students. The results were tabulated for 294 females.

\subsection{Lifestyle}

\subsubsection{Bedtime (Table 1)}

As a result of the survey, the most common bedtime among female college students was 95 students at 24:00 $(32.3 \%)$, followed by 93 at $25: 00(31.6 \%), 75$ at $26: 00$ $(25.5 \%), 14$ at $23: 00(4.8 \%), 9$ at $27: 00(3.1 \%), 3$ at $22: 00$ and after 28:00 (1\%), and 2 before 21:00 (0.7\%). The good condition group indicated 66 at 24:00 (36.2\%), 55 at 25:00 $(30.2 \%), 49$ at $26: 00(26.9 \%), 8$ at $23: 00(4.4 \%), 2$ at $27: 00$ $(1.1 \%), 1$ before $21: 00$ and after $28: 00(0.5 \%)$, and 0 at 22:00, indicating an average bedtime in the good condition group of $24.9 \pm 1.0$ o'clock.

The constipation group indicated 38 students at 25:00 (33.9\%), the most common, followed by 28 at $24: 00(25.2 \%)$, 26 at $26: 00(23.2 \%), 7$ at 27:00 (6.3\%), 6 at 23:00 (5.4\%), 3 at 22:00 (2.7\%), and 2 before 21:00 and after 28:00 (1.8\%). The average bedtime in the constipation group was at $24.9 \pm 1.4$ o'clock.

\subsubsection{Wake up Time (Table 1)}

The overall wake-up time indicated 91 students at 7:00 (31.0\%), the most common, followed by 80 at 8:00 (27.2\%), 78 at 6:00 (26.5\%), 18 at 9:00 (6.1\%), 13 at 5:00 (4.4\%), 9 after $10: 00(3.0 \%), 4$ at $4: 00$, and 1 before 3:00 (3.0\%). The good condition group indicated 64 at 8:00 (34.5\%) and 56 at 7:00 (30.2\%), as the most common, followed by 35 at $6: 00(18.9 \%)$, 
16 at 9:00 (8.9\%), after 10:00 (4.3\%), 2 at 4:00 (1.6\%), 1 at 5:00 $(1 \%), 0$ before $3: 00$, indicating an average wake-up time of $7.5 \pm 1.2$ o'clock. The constipation group indicated 43 at $6: 00$ $(38.4 \%)$ and 35 at $7: 00(31.2 \%)$, as the most common, followed by 16 at 8:00 (14.3\%), 12 at 5:00 (10.7\%), 2 at 9:00 and 4:00 $(1.8 \%), 1$ after 10:00 and before 3:00 (0.9\%), indicating an average wake-up time of $7.6 \pm 2.0$ o'clock.

\subsubsection{Hours of Sleep (Table 1)}

The overall results indicated 108 students for 6 hours (36.7\%), the most common, followed by 93 for 7 hours $(31.6 \%), 49$ for 8 hours (16.7\%), 28 for 5 hours $(9.5 \%), 6$ for 9 hours $(2.0 \%), 4$ for 4 hours $(1.3 \%)$, and 3 for 3 hours or less and 10 hours or more $(1.0 \%)$. The good condition group indicated 65 for 6 hours (35.7\%), 58 for 7 hours (31.9\%), 33 for 8 hours (18.1\%), 16 for 5 hours $(8.8 \%), 4$ for 10 hours or more $(2.2 \%)$, and 2 for less than 3 hours, 4 hours and 10 hours or more (1.0\%). The average hours of sleep for the good condition group was $6.6 \pm 1$.1 hours. The constipation group indicated 43 for 6 hours $(38.4 \%)$, the most common, followed by 35 for 7 hours (31.3\%), 16 for 8 hours (14.3\%), 12 for 5 hours (10.8\%), 2 for 4 hours and 9 hours $(1.8 \%), 1$ for 3 hours or less and 10 hours or more $(0.9 \%)$, indicating an average hours of sleep in the constipation group of $6.5 \pm 1.2$ hours.

\subsubsection{Breakfast (Table 2)}

Overall, 164 students $(55.8 \%)$, the most common, answered that they "eat every day," followed by 52 students who "eat 2-3 days a week" (17.7\%), 45 who "eat 4-5 days a week" (15.3\%), and 33 who "hardly eat" (11.2\%). The good condition group indicated 110 students who "eat every day" $(60.4 \%)$, the most common, followed by 30 students who "eat 2-3 days a week" (16.5\%), 22 who "eat 4-5 days a week" $(12.1 \%)$, and 20 who "hardly eat" $(11.0 \%)$. Even the constipation group indicated 54 who "eat every day" (45.5\%), the most common, followed by 23 who "eat 4-5 days a week" (20.5\%), 22 who "eat 2-3 days a week" (19.6\%), and 13 who "hardly eat" (11.6\%).

\subsubsection{Alcohol Drinking (Table 3)}

Regarding alcohol drinking, overall, 96 students responded that they "drink a few times a month" (32.7\%), the most common, followed by 79 who "almost never drink" (26.9\%), 70 who drink "2 to 3 times a week" (23.8\%), and 49 who "drink every day" (16.7\%). The good condition group indicated a result of 81 who "drink 2-3 times a month" (44.5\%), 79 who "drink little" (43.4\%), 19 who "drink 2-3 times a week" (10.4\%), and 3 who "drink every day" (1.6\%). The constipation group indicated 51 who "drink 2-3 times a week" $(45.5 \%)$, the most common, followed by 46 who "drink daily" (41.1\%), 15 who "drink 2-3 times a month" (13.4\%), and 0 who "almost never drink."

\subsubsection{Smoking (Table 4)}

Overall, 10 students (3.4\%) responded that they "smoke," while $284(96.6 \%)$ responded that they did not smoke. Of these, 10 who answered they "smoke" were in the good condition group, while none of the constipation group answered they "smoke". The average number of cigarettes smoked per day by those who answered they "smoke" was 6.5 .

\subsubsection{Exercise (Table 5)}

Regarding the frequency of exercise, they answered "almost no exercise," the most common, in both the good condition group and the constipation group, indicating 91 $(50.0 \%)$ in the good condition group and $61(54.5 \%)$ in the constipation group. Both the good condition group and the constipation group responded, "about once a week," "about 2 to 4 times a week," and "every day" in descending order.

Table 1. Bedtime, wake-up time, and hours of sleep according to state of constipation Good condition Constipation.

\begin{tabular}{|c|c|c|}
\hline Bedtime & Good condition & Constipation \\
\hline Before 22:00 & $1(0.55)$ & $2(1.85)$ \\
\hline 23:00 & $8(4.35)$ & $6(5.45)$ \\
\hline $24: 00$ & $66(36.3)$ & $29(26.4)$ \\
\hline $25: 00$ & $55(30.2)$ & $38(34.5)$ \\
\hline $26: 00$ & 49 (26.9) & $26(23.6)$ \\
\hline $27: 00$ & $2(1.10)$ & $7(6.36)$ \\
\hline After 28:00 & $1(0.55)$ & $2(1.82)$ \\
\hline Wake-up time & Good condition & Constipation \\
\hline Before 4:00 & $0(0)$ & $1(0.90)$ \\
\hline $5: 00$ & $2(1.10)$ & $1(0.90)$ \\
\hline $6: 00$ & $1(0.55)$ & $1(0.90)$ \\
\hline $7: 00$ & $35(19.2)$ & $23(20.5)$ \\
\hline $8: 00$ & $56(30.8)$ & $35(0.90)$ \\
\hline 9:00 & $64(35.2)$ & $26(23.2)$ \\
\hline $10: 00$ & $16(8.80)$ & $17(15.2)$ \\
\hline After 11:00 & $8(4.40)$ & $8(7.14)$ \\
\hline Hours of sleep & Good condition & Constipation \\
\hline 3 hours or less & $2(1.10)$ & $1(0.90)$ \\
\hline 4 hours & $2(1.10)$ & $2(1.80)$ \\
\hline 5 hours & $16(8.80)$ & $12(10.7)$ \\
\hline 6 hours & $65(35.7)$ & $43(38.4)$ \\
\hline 7 hours & $58(31.9)$ & $35(31.3)$ \\
\hline 8 hours & $33(18.1)$ & $16(14.3)$ \\
\hline 9 hours & $4(2.20)$ & $2(1.80)$ \\
\hline 10 hours or more & $2(1.10)$ & $1(0.90)$ \\
\hline
\end{tabular}

N. S.

Table 2. Breakfast consumption status by state of constipation Good condition Constipation.

\begin{tabular}{lll}
\hline & Good condition & Constipation \\
\hline Eat everyday & $110(60.4)$ & $54(48.2)$ \\
Eat about 3-4 times a week & $22(12.2)$ & $23(20.5)$ \\
Eat about 2-3 times a week & $30(16.5)$ & $22(19.6)$ \\
Hardly eat & $20(11.0)$ & $13(11.6)$ \\
\hline
\end{tabular}

Frequency in the good condition group and constipation group $\mathrm{p}<0.01$

Table 3. Alcohol consumption status by state of constipation Good condition Constipation.

\begin{tabular}{lll}
\hline & Good condition & Constipation \\
\hline Drink everyday & $3(1.65)$ & $46(40.7)$ \\
Drink 2-3 times a week & $19(10.4)$ & $51(45.5)$ \\
Drink 2-3 times a month & $81(44.5)$ & $15(13.4)$ \\
Hardly drink & $79(43.4)$ & $0(0)$ \\
\hline
\end{tabular}

Frequency in the good condition group and constipation group $\mathrm{p}<0.01$ 
Table 4. Smoking status by state of constipation Good condition Constipation.

\begin{tabular}{lll}
\hline & Good condition & Constipation \\
\hline $\begin{array}{l}\text { Smoke } \\
\text { Do not smoke }\end{array}$ & $10(5.50)$ & $0(0)$ \\
& $172(94.5)$ & $112(100)$ \\
\hline N. S. & & \\
& & \\
$\begin{array}{l}\text { Table 5. Exercise } \\
\text { Constipation. }\end{array}$ & & \\
\hline & Good condition & Constipation \\
\hline $\begin{array}{l}\text { Exercise almost everyday } \\
\text { Exercise about 2-4 times a week }\end{array}$ & $9(4.95)$ & $7(6.25)$ \\
$\begin{array}{l}\text { Exercise about once a week } \\
\text { Hardly exercise }\end{array}$ & $55(30.8)$ & $19(17.0)$ \\
\hline
\end{tabular}

N. S.

\subsection{State of Defecation}

\subsubsection{Awareness of Bowel Movements (Table 6)}

Regarding the awareness of bowel movements, 152 (83.5\%) answered "normal" in the good condition group, wherein 27 (14.8\%) were aware of "constipation" and $3(1.7 \%)$ were aware of "diarrhea." The constipation group indicated that 63 (56.2\%) were aware of "constipation," while $44(39.3 \%)$ were aware of "normal" and 5 (4.5\%) were aware of "diarrhea."

\subsubsection{Frequency of Defecation (Table 7)}

"Once a day" was the most common answer selected by 105 students $(57.7 \%)$ in the good condition group, followed by $50(27.5 \%)$ who selected "once every two days," with most found to defecate once every two days, as a result. The constipation group indicated 41 people for "once every 3 to 4 days" $(36.6 \%)$, followed by 38 for "once every 2 days" $(34.0 \%)$. The results indicated that few students in the constipation group had bowel movements every day. Furthermore, the answer "once a week" was found in "Other" in the constipation group.

\subsubsection{Regularity (Table 8)}

The good condition group indicated 76 for "after breakfast" $(41.6 \%)$, the most common, and 15 for "after waking up" $(8.2 \%)$, the least common. The constipation group indicated 72 for "irregular" bowel movements $(64.3 \%)$ and 4 for "after waking up" (3.6\%), the least.

Table 6. Awareness of bowel movements by state of constipation Good condition Constipation.

\begin{tabular}{lll}
\hline & Good condition & Constipation \\
\hline Somewhat constipated & $27(14.8)$ & $63(56.2)$ \\
Normal & $152(83.5)$ & $44(39.3)$ \\
Somewhat diarrhea & $3(1.65)$ & $5(4.46)$ \\
\hline
\end{tabular}

Frequency in the good condition group and constipation group $\mathrm{p}<0.05$

\subsubsection{Defecation Time (Table 9)}

Both the good condition group and the constipation group indicated "within 5 minutes" as the most common answer, with $149(81.9 \%)$ in the good condition group and 70 people $(62.5 \%)$ in the constipation group, followed by "5 to 10 minutes" and "10 minutes or more."

Table 7. Frequency of defecation by state of constipation Good condition Constipation.

\begin{tabular}{lll}
\hline & Good condition & Constipation \\
\hline Once a day & $105(57.7)$ & $23(20.5)$ \\
Twice a day & $16(8.80)$ & $6(5.40)$ \\
Three times or more a day & $2(1.10)$ & $2(1.80)$ \\
Once every two days & $50(27.5)$ & $38(34.0)$ \\
Once every 3-4 days & $9(4.94)$ & $41(36.6)$ \\
Other & $0(0)$ & $2(1.80)$ \\
\hline
\end{tabular}

Frequency in the good condition group and constipation group $\mathrm{p}<0.01$

Table 8. Regularity of bowel movements by state of constipation Good condition Constipation.

\begin{tabular}{lll}
\hline & Good condition & Constipation \\
\hline After waking up & $15(8.24)$ & $4(3.57)$ \\
After breakfast & $76(41.6)$ & $18(16.1)$ \\
After lunch to evening & $32(17.6)$ & $16(14.3)$ \\
Irregular & $57(31.3)$ & $72(64.3)$ \\
Other & $2(1.10)$ & $2(1.79)$ \\
\hline
\end{tabular}

Frequency in the good condition group and constipation group $\mathrm{p}<0.05$

Table 9. Defecation time by state of constipation Good condition Constipation

\begin{tabular}{lll}
\hline & Good condition & Constipation \\
\hline Within 5 minutes & $149(81.9)$ & $70(61.9)$ \\
$5-10$ minutes & $30(16.5)$ & $36(32.1)$ \\
10 minutes or longer & $3(1.65)$ & $6(5.36)$ \\
\hline
\end{tabular}

Frequency in the good condition group and constipation group $\mathrm{p}<0.05$ 


\subsection{Stress (Table 10)}

Negative life events and positive life events were classified into interpersonal and achievements, respectively, and the scores were compared between the good condition group and the constipation group. In terms of negative life events, the value was higher in the constipation group than in the good condition group, while the value was higher in the good condition group than in the constipation group in terms of positive life events.

Table 10. Scores of negative life events and positive life events by state of constipation.

\begin{tabular}{lllll}
\hline & Negative life events & & Positive life events & Constipation \\
\hline Overall & Good condition & Constipation & Good condition & $8.77 \pm 3.39^{*}$ \\
Interpersonal & $7.95 \pm 5.32$ & $9.16 \pm 5.51^{*}$ & $9.37 \pm 3.19$ & $4.99 \pm 3.50$ \\
Achievements & $3.78 \pm 3.10$ & $4.68 \pm 2.92 *$ & $5.88 \pm 3.47$ & $13.76 \pm 5.98 * *$ \\
\hline
\end{tabular}

${ }^{*} \mathrm{p}<0.05$

$* * \mathrm{p}<0.01$

\section{Discussion}

The average bedtime in the good condition group was at 24.8 o'clock, while the average bedtime in the constipation group was at $25.0 \mathrm{o}$ 'clock, indicating a slightly earlier time in the good condition group, although the difference was not great. The average wake-up time was 7.45 o'clock in the good condition group and 7.57 o'clock in the constipation group, while the average hours of sleep was 6.64 hours in the good condition group and 6.51 hours in the constipation group. Although no significant differences were observed, it is considered that the good condition group tended to sleep a little longer, due to the habit of getting to bed early and rising early.

The average points were examined in terms of how often they ate breakfast, with 1 point for "eating every day," 2 points for "eating 4-5 times a week," 3 points for "eating 2-3 times a week," and 4 points for "hardly eating." The good condition group indicated a score of 1.79 , while the constipation group indicated a score of 1.96, slightly lower in the good condition group, indicating a significantly higher frequency of having breakfast.

Comparing the frequency of defecations with breakfast revealed that many students who eat breakfast every day defecate after breakfast, indicating a significant difference. As expected, eating breakfast every day activates the movement of the stomach and intestines, making it easy to defecate immediately after breakfast.

A previous study [19] indicated that the gastrointestinal tract had a circadian rhythm (a physiological phenomenon that fluctuates in a cycle of approximately 24 hours) and although it did not move during sleep, it began to move upon awakening, causing larger giant migrating contractions (GMC) at this time, where was effective for defecation. In other words, getting sufficient sleep allows the intestinal tract to rest, while eating breakfast stimulates the intestinal tract, that started to work upon awakening, and induces large migrating contractions via the gastric/colonic reflex, making it easier to defecate as a result. Although it is not clear which affects which, between the sleep state or the bowel movement state, it is believed that they influence each other and it has been reported that peptides derived from colon and intestinal bacteria act as sleep substances via cytokines, with changes in the intestinal bacteria affecting non-REM sleep [20-22]. The compilation of a few more results or adding questions such as how long we should wait after getting up to have breakfast may have yielded different results.

According to a previous study [23], when comparing the constipation group and the good condition group, the total food intake in the constipation group was significantly lower. A comparison by food group indicated that the sufficiency rate of cereals, potatoes, fruits, and vegetables (green and yellow vegetables + other vegetables), that are high in dietary fiber, along with meat which is rich in fat, was significantly low in the constipation group. Upon comparing the constipation group and the good condition group, the results indicated that the constipation group had a particularly low intake of energy, protein, lipids, carbohydrates, magnesium, zinc, vitamin B1, vitamin B6, and dietary fiber (especially water-soluble dietary fiber). In other words, it is indicated that those in the constipation group eat a fairly small amount of food and eat only simple meals. This is also because the constipation group often lived alone. If you live alone, meals tend to be simple and unstable, such that sometimes you eat and other times you do not. Therefore, it is considered that constipation in young women is caused by a lack of constant food intake, irregular meal times, and night-oriented lifestyle.

Based on the above, in this study, while we only compiled questionnaires on how often they ate breakfast, examining the amount and content of meals and nutritional groups may have yielded different results.

There was a significant difference in the awareness of bowel movements between the good condition group and the constipation group. Judging from this, it is considered that many students in the constipation group are aware that they suffer from constipation. There was also a significant difference in the frequency of defecations between the good condition group and the constipated group. Therefore, it became clear that they felt their condition was good if they had bowel movements every day and became aware of constipation if they had bowel movements once every two days or more. 
In addition, there was a significant difference between the good condition group and the constipation group, in terms of the time required for defecation and regularity. Comparing the good condition group and the constipation group, it was clarified that the constipation group took longer to defecate than the good condition group and defecation was irregular. It is presumed that eating breakfast affects defecation, and as a result, defecation is likely to occur regularly.

Comparing the average and standard deviation, respectively, the results indicated that the constipation group was higher in terms of negative life events than the good condition group, while the constipation group was higher in terms of positive life events. Based on this, it was inferred that mentally burdensome events in daily life may cause constipation. It is believed that constipation can be suppressed by events that make one feel mentally relaxed or feel better in daily life. Furthermore, when positive life events were classified into two categories, "interpersonal" and "achievements," while no significant difference was found in "interpersonal," a significant difference was found in "achievements." Judging from this, it can be inferred that, among college students, the feeling of accomplishment and recognition of accomplishing something is more closely related to constipation than interpersonal relationships such as friendships. A study investigating physical symptoms caused by mental changes during the peri-menstrual period of female college students, with regard to the physical changes caused by positive factors, indicated that active factors such as achieving things resulted in "increased appetite" and "spending actively," indicating a possible relationship with constipation [24]. However, there are various other possible factors that cause constipation, so it is possible that the mental stress received from daily events is not necessarily related to constipation.

While this study examined the relationship between state of defecation and lifestyle using a questionnaire, it is assumed that question items such as those related not only to lifestyle but also to habitual constipation should have been included. It is believed that habitual constipation, which is said to be caused by repeated endurance of constipation, is common in children today, so it might have been necessary to consider this possibility in addition to constipation caused by basic lifestyle [25].

\section{Conclusion}

Upon examining the relationship between the state of defecation of college students and lifestyle, the following was considered.

It was revealed that the constipation group lacked hours of sleep compared with the good condition group. Regarding breakfast, it was found that the constipation group had a tendency to skip more frequently than the good condition group. It was found that the constipation group tended to drink alcohol more frequently than the good condition group. There was no difference in smoking between the good condition group and the constipation group. There was also no difference in the frequency of exercise between the two groups, with the most common answer being that they did little exercise.

Regarding the relationship between state of defecation and stress, the average score of the constipation group was higher than that of the good condition group in terms of both interpersonal and achievement items for negative life events. The average scores for both of the two items for positive life events were higher in the good condition group. It was inferred that interpersonal relationships might easily affect the state of defecation among female college students.

\section{References}

[1] Preston, D. M. and Lennard-Jones, J. E. (1986) Severe chronic constipation of young women: 'idiopathic slow transit constipation'. Gut, 27, 41-48.

[2] Zuo-Liang, X., Victor, P., Piero, B. and Jose, B. (2005) Role of progesterone signaling in the regulation of G-protein levels in female chronic constipation. Gastroenterology, 128, 667-75.

[3] Oettle, G. J. (1991) Effect of moderate exercise on bowel habit. Gut, 32, 941-944.

[4] Alayne, D., M., Olafur, P., Patricia, S. G., Kathryn, L. B., Jan, B. and William, E. W. (2013) Association of low dietary intake of fiber and liquids with constipation: evidence from the National Health and Nutrition Examination Survey. Am J Gastroenterol, 108, 796-803.

[5] Laurent, D., Walter, C. W. and Edward, L. G. (2003) Association between physical activity, fiber intake, and other lifestyle variables and constipation in a study of women. $\mathrm{Am} \mathrm{J}$ Gastroenterol, 98, 1790-6.

[6] Arnaud, M. J. (2003) Mild dehydration: a risk factor of constipation? European Journal of Clinical Nutrition volume, $57, \mathrm{~S} 88-\mathrm{S} 95$.

[7] Quigley, E. M. (2011) The enteric microbiota in the pathogenesis and management of constipation. Clinical Gastroenterology, 25, 119-126.

[8] Cheng, C., Chan, A. O. O., Hui, W. M. and Lam, S. K. (2003) Coping strategies, illness perception, anxiety and depression of patients with idiopathic constipation: a population-based study. Aliment Pharmacol Ther, 18, 319-26.

[9] Ochiai, T. (2003) Effects of stress on colon in the canine. Journal of Japanese Society of Gastroenterology, 87, 965-972 (in Japanese).

[10] Niranga, M. D. and Shaman, R. (2010) Association between Constipation and Stressful Life Events in a Cohort of Sri Lankan Children and Adolescents. Journal of Tropical Pediatrics, 56, 144-148.

[11] Hiratsuka, H. (1990) Women and Constipation. Journal of Japan Society of Coloproctology, 43, 1070-1076 (in Japanese).

[12] Yang, L., Liang, L., Yi, Y., Yuxi, H., Yanli, Z., Miao, W., Shuo, C. and Shukun, Y. (2014) A school-based study of irritable bowel syndrome in medical students in beijing, china: prevalence and some related factors. Gastroenterol Res Pract, Volume 2014, Article ID 124261, 8 pages. 
[13] George, F. L., W Grant, T., William, D. C., Lesley, A. H., Fermin, M. and Robin, C. S. (2006) Functional bowel disorders. Gastroenterology, 130, 1480-91.

[14] Douglas, A. D. (2006) The functional gastrointestinal disorders and the Rome III process. Gastroenterology, 130, 1377-90.

[15] Douglas, A. D. and Dan, L. D. (2006) Rome III: New standard for functional gastrointestinal disorders. J Gastrointestin Liver Dis, 15, 237-41.

[16] Takahira, M. (1998) Construction of a scale of life events in interpersonal and achievement domains for undergraduate students. Japan Journal of Social psychology, 14, 12-24 (in Japanese).

[17] Ozeki, Y., Haraguchi, M. and Tsuda, A. (1994) A Covariance Structural Analysis to the Psychological Stress Process in University Students. The Japanese Journal of Health Psychology, 7, 20-36 (in Japanese).

[18] Needles, D. J. and Abramson, L. Y. (1990) Positive life events, attributional style, and hopefulness: Testing a model of recovery from depression. Journal of Abnormal Psychology, $99,156-165$.

[19] Hosoda, S. (2004) Life style and discomfort on defecation. Juntendo Medical Journal, 50, 330-337 (in Japanese).
[20] Carol, A. E. and Linda, A. T. (2000) Systemic bacterial invasion induced by sleep deprivation. $\mathrm{Am} J$ Physiol Regulatory Integrative Comp Physiol, 278, R905-R916.

[21] Pollmächer, T., Schreiber, W., Gudewill, S., Vedder, H. Fassbender, K., Wiedemann, K., Trachsel, L., Galanos, C. and Holsboer, F. (1993) Influence of endotoxin on nocturnal sleep in humans. Am J Physiol, 264, R1077-83.

[22] Obal, F. Jr., Opp, M., Cady, A. B., Johannsen, L. and Krueger, J. M. (1989) Prolactin, vasoactive intestinal peptide, and peptide histidine methionine elicit selective increases in REM sleep in rabbits. Brain Research, 490, 292-300.

[23] Kimura, Y., Shimada, R., Matsuda, K. and Takumi, H. (2004) Relationship between Constipation and Dietary Habits in Female Junior College Students. Research reports of Yamawaki Gakuen Junior College, 42, 16-26 (in Japanese).

[24] Kagawa, K., Kitamura, Y., Ninomiya, H. and Terashima, S. (2010) Studies of Premenstrual Symptoms in Young Females : Frequency of Premenstrual Symptoms and Construction of the Premenstrual State Scales. Japanese Society of Psychosomatic Medicine, 50, 659-665 (in Japanese).

[25] Goto, C., Tokudome, Y. (1999) Relationship between Defecation and Life Style in Women College Students. Journal of Nagoya Bunri University, 24, 81-86 (in Japanese). 